\title{
Phenotypic associations between gestation length and production, fertility, survival, and calf traits
}

\author{
G. M. Jenkins, ${ }^{*}$ P. Amer, ${ }^{* 1}$ K. Stachowicz, ${ }^{*}$ and S. Meier† \\ *AbacusBio Limited, PO Box 5585, Dunedin 9058, New Zealand \\ †DairyNZ, Private Bag 3221, Hamilton 3240, New Zealand
}

\begin{abstract}
Gestation length may be a useful selection criterion in the genetic evaluation of fertility for New Zealand's predominantly seasonally calving dairy herd. However, it is unknown if calves born following shorter gestation lengths have lower survival or are compromised in their subsequent performance as a milking cow. In this study, data from a large number $(\sim 38,000)$ of cows were first analyzed to determine if those animals born following a short (shortest 5\%) or a long (longest 5\%) gestation length differed in their subsequent fertility, milk production, and survival compared with intermediate-gestation-length animals. To determine the effect of gestation length on calving difficulty and perinatal mortality, the gestation records of the calves born to these cows (from their heifer and subsequent 6 parities) were also analyzed. Animals born following short gestation lengths had improved fertility (specifically, their probability of being presented for mating in the first 21 $\mathrm{d}$ of the mating season was increased by 4 to 5 percentage points and the day of the calving season at which they calved was 2 to $5 \mathrm{~d}$ earlier), whereas those born following long gestation lengths had decreased fertility ( 3 to $4 \%$ less likely to be presented for mating in the first $21 \mathrm{~d}$ of the calving season and calved 3 to $5 \mathrm{~d}$ later) compared with animals with average gestation lengths. Both short- and long-gestation-length animals produced significantly less milk and solids (e.g., 1.3 to $1.4 \mathrm{~kg}$ of protein over a standardized 270-d lactation) relative to intermediate-gestation-length cows, after adjusting for the day of the year they were born. However, for shortgestation-length cows, this effect disappeared when the earlier birth advantage was retained. Short-gestationlength cows did not exhibit a significant reduction in survival compared with intermediate-gestation-length cows. Short gestation length did not affect calving difficulty but long gestation length was negatively associ-
\end{abstract}

Received June 9, 2015.

Accepted September 15, 2015.

${ }^{1}$ Corresponding author: pamer@abacusbio.co.nz ated with this trait (i.e., about $2 \%$ higher incidence). Calves gestated for shorter or longer periods were more likely to die in the perinatal period than other calves (3 and 7\% higher incidence of mortality, respectively). Overall, the net effects of shortened gestation lengths are likely to be economically positive.

Key words: gestation length, survival, production, fertility

\section{INTRODUCTION}

Gestation length (GL) is a highly heritable trait (Winkelman and Spelman, 2001; Hansen et al., 2004) and can be easily calculated using mating and calving data in the New Zealand dairy industry. Estimated breeding values currently exist for gestation length direct (GLd, the effect of the calf's own genes on its gestation length), although it is not included in the fertility genetic evaluation model and no direct economic weighting is applied to the trait within the national breeding objective (breeding worth, BW). The benefits of including GL as a correlated predictor trait in the fertility genetic evaluation model and breeding objective is that it is highly heritable and has a high genetic correlation with the trait calving season day (CSD), which defines the day of the calving season on which the cow calved (K. Stachowicz, unpublished data). A strong correlation between gestation length and calving season day is not unexpected because of the part-whole relationship of these traits. In the seasonal calving dairy production systems of New Zealand, cows that have poorer fertility typically have a lower chance of being presented for mating within the first $21 \mathrm{~d}$ of the mating season and calve later in the calving season. This means that GL has the potential to increase the accuracy of the fertility EBV predictions, particularly for bulls whose daughters have been born or calved themselves but have not yet expressed fertility traits. In addition, because of the seasonal nature of mating and calving in the New Zealand dairy industry, service sires with EBV for shorter GLd improve the mating and conception opportunities for the cows they are mated to, a benefit that is independent of the increase in ac- 
curacy of the fertility EBV due to the use of GL as a correlated trait. Therefore, potential economic benefits can be realized by including GL in the fertility genetic evaluation analysis as a correlated trait (indirect selection) and in the breeding objective (direct selection).

However, these steps first require careful consideration of the link between calf GL and perinatal mortality, and the link between GL of the cow herself and her future milk production, fertility, and survival. Many studies have reported a link between GL and perinatal mortality and calving difficulty. Some have reported associations between short GL (e.g., <272 d) and increased perinatal mortality (Bleul, 2011). Others have reported associations between long GL and perinatal mortality often as a result of dystocia (McGuirk et al., 1998; Chassagne et al., 1999) and yet other studies have reported associations between extreme GL and perinatal mortality (Johanson and Berger, 2003; Hansen et al., 2004; Norman et al., 2011). These studies have typically focused on how service sire GL affects calf traits (mortality/calving difficulty) or the subsequent performance of the cow that carried the calf. Norman et al. (2011) found a positive linear relationship between days open (a fertility trait) and GL: cows gestated for shorter periods tended to have improved fertility during their first lactation. Norman et al. (2011) also found that the cows that performed best for milk production and had the most favorable productive life and culling records tended to have been born following intermediate GL (approximately 274-279 d). In the same study, those cows gestated for shorter than optimum periods were less affected in terms of milk production and productive life than were those cows gestated for longer periods.

Few other studies have focused on the effects of GL of the cow before her birth and on her subsequent performance. Furthermore, the majority of gestation length studies have focused on the Holstein breed and all-year calving systems. The objective of this study was to ascertain the risks associated with a genetic reduction in GL, due to either direct or indirect selection, in terms of future fertility, production, BCS, and survival in cows and survival and perinatal mortality in calves in the New Zealand seasonal calving system.

\section{MATERIALS AND METHODS}

\section{Data}

Records for over 40,000 cows and their calves from Livestock Improvement Corporation (LIC, Hamilton, New Zealand) sire proving scheme (SPS) herds born from 1997 to 2013 inclusive were analyzed. A detailed list of variables studied is presented in Table 1 . The data set included contemporary group (herd-year-age category of the dam where age differentiates first vs. subsequent lactation), mating dates during the first 3 lactations and the first 4 calving dates; GL; 270-d milk, fat, and protein yields, protein and fat percentages, and fat to protein ratio (FPR) based on yields from 270-d milk data, all from lactation 1; the age at which each cow exited the herd (CullAge); BCS recorded during first lactation; as well as calf fate and calving difficulty (Cdiff) of the cows' calves. Minimum eligibility for a cow's records to be considered was that the cow must have both a first calving and a first mating data record.

Only seasonal mating and calving events were used; that is, mating events between September and January and calvings between June and November, inclusive. Age of the cow at calving was edited to include only cows within a specified age group, according to DairyNZ contemporary group age classes (DairyNZ, 2007). The calving age ranges were 548-913, 914-1,278, and 1,279-1,643 d for first, second, and third calvings, respectively. Mating interval was calculated as the difference in days between first and last recorded mating. Last mating date, within season, was set to missing when the mating interval was greater than $110 \mathrm{~d}(\sim 5$ estrus cycles). Calving interval was calculated as the difference in days between consecutive calvings. Data were filtered to exclude records with calving intervals $<300$ or $>550 \mathrm{~d}$ in length. Gestation length was calculated as the difference in days between last recorded mating and the subsequent calving. Data were filtered to exclude GL $<265$ and $>295 \mathrm{~d}( \pm 3 \mathrm{SD})$. Any cows with an unknown sire or dam were excluded. Data were also edited to exclude records from cows with breed composition other than Holstein-Friesian and Jersey. Mating and calving records with recorded synchronizations (controlled internal drug release, CIDR; 6\%), inductions $(<3 \%)$, and abortions $(0.3 \%)$ were set to missing in the data set. This did not necessarily lead to missing fertility phenotypes in the final data set, as cows that were mated but did not calve as a result of this mating (i.e., had a missing calving record) were penalized according to Donoghue et al. (2004) by having a penalty record assigned as $21 \mathrm{~d}$ added to the longest CSD record within their contemporary group. Mating dates were converted to binary scores (PM21b1, PM21b2, and PM21b3 for mating during the first 3 lactations, respectively) with a score of 1 assigned when the cow was mated within $21 \mathrm{~d}$ of the planned start of mating for the contemporary group defined specifically for each herd and year cohort, and 0 otherwise. Calving dates were converted to CSD, defined as the number of days from the planned start of calving to the caving date. Planned start of calving was defined for each herd-year cohort as the previous planned start of mat- 
ing date plus $282 \mathrm{~d}$. Cows with missing mating records had their record for PM21b set to 0 if their CSD record was $>42$; PM21b was set to 0 and CSD penalized by having $21 \mathrm{~d}$ added to the longest CSD record in their contemporary group for cows with mating or calving phenotypes missing but that were recorded as being culled for fertility-related reasons.

Contemporary groups with fewer than 10 firstlactation cow records were deleted from the data set. The data showed an excess of GL records equal to 282 d (Figure 1). These records were assumed a default parameter in the database and the true GL records unknown. All GL records of $282 \mathrm{~d}$ were therefore set to missing. Although this meant that some data were lost (i.e., heifers who legitimately had a GL of $282 \mathrm{~d}$ ), there was a huge surplus of data in the middle category and no detrimental effect on results was anticipated. The final data set contained GL records for 38,115 cows. This data set was used to analyze the effect of GL on fertility and production traits.

In total, 49,352 calving records were available for these cows. Each calving was associated with a recorded sire (including both natural mated and AI sires), sire official code (a measure of certainty as to the sire of the calf), calving date, sex, contemporary group, GL, fate code $(1=$ dead, $0=$ alive $)$, and calving difficulty $(1=$ yes, $0=$ no $)$. These calving records were edited to include only calves born between 1997 and 2013 (inclusive), born as singletons; with GL between 265 and 295 d (inclusive) and excluding GL of 282 d; with fates recorded as bobbied (typically culled between $4 \mathrm{~d}$ and 1-2 mo after birth), culled, died, reared, or sold; and those with pregnancy terms not recorded as abortions, inductions, or premature.

\section{GL Categories}

The GL categories were assigned to trait records to facilitate contrasting performance of the categories. Thus, cow traits including cow milk production, fertility, survival, and BCS traits were apportioned into different GL categories, based on their own GL before their birth. The cows with the shortest 5\% (265-273 d, mean 271.9 d) of GL records were classed as GL category 1, the longest 5\% (289-295 d, mean $290.3 \mathrm{~d}$ ) of GL records were classed as GL category 3, and the remaining records classified as GL category 2 (274-288 d, mean $280.7 \mathrm{~d}$ ).

Calving traits, including calving difficulty and calf fate, were categorized according to the distribution of GL records of the calves themselves. The shortest $5 \%$ (265-274 d, mean 272.7 d) of GL records were classed as GL category 1, the longest 5\% (290-295 d, mean 291.3 d) of GL records were classed as GL category 3, and the remaining records classified as the intermediate GL category 2 (275-289 d, mean 281.5 d). On average, those in the shortest GL category were born $10 \mathrm{~d}$ earlier than those in the intermediate GL category, whereas animals in the longest GL category were born $10 \mathrm{~d}$ later than those in the intermediate GL category. Further

Table 1. Trait abbreviations and descriptions

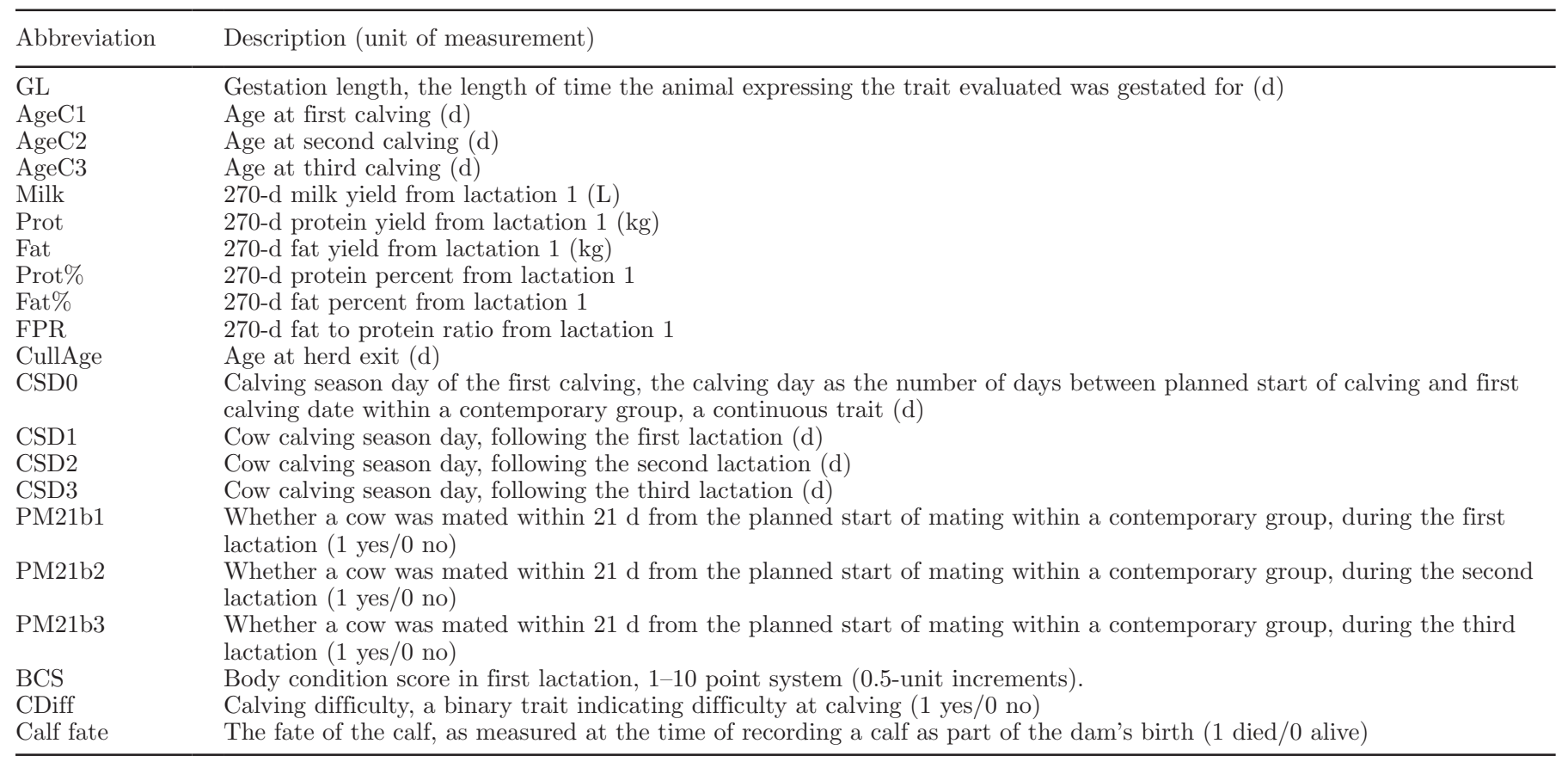




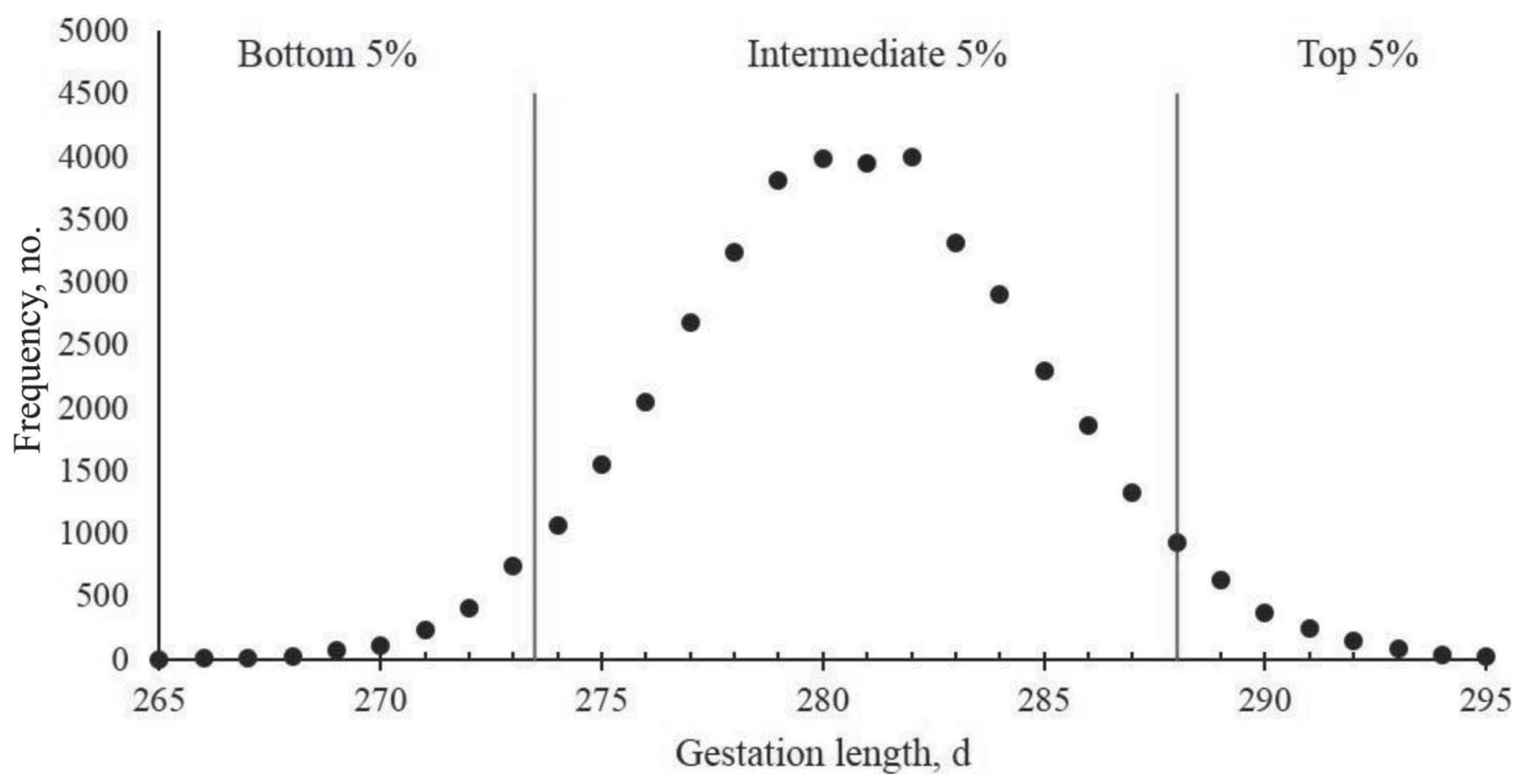

Figure 1. Distribution of gestation length, in the edited data set (before gestation lengths of $282 \mathrm{~d}$ removed).

data statistics for each GL category for both cows and calves are presented in Tables 2 and 3 .

\section{Data Analysis}

The mean values of the production, fertility, and survival traits for each GL category were calculated. Fixed effect models were fitted to the data to determine the effect of GL category on the production, fertility, and survival traits: first-lactation (270-d yield) milk, protein, fat, protein percent, fat percent, FPR, CSD (for heifers and subsequent 3 cow calvings), presence or absence of a mating record within $21 \mathrm{~d}$ of the planned start of mating (PM21, for 3 cow matings) as defined by Harris et al. (2006), age at culling, BCS (scale of 1-10; Roche et al., 2004), calf fate, and calving difficulty. Models were implemented using the PROC GLM procedure in SAS (SAS Institute, 2014), where the type 3 sum of squares $F$-statistic was used to test parameter significance, and a $t$-test used to test the significance of individual GL category effects. Each model was run twice, once with cow birth day of the year fitted (Dob; as a Julian day of the year) and once without. This provided an estimate of the effect of GL alone versus the combined effect of also being born earlier in the season due to short GL.

All fertility traits (except heifer CSD) were analyzed with the same model as that used in the national ge- netic evaluation of fertility traits (Harris et al., 2006) but without the random genetic effects of animal and permanent environmental effects fitted:

$$
\begin{aligned}
y & =G L c a t+D o b+C G+\text { age }+ \text { breed }+ \text { age } \cdot \text { breed }+H F_{F R} \\
& +H F_{N Z}+H E T_{J E x N Z}+H E T_{J E x F R}+H E T_{N Z x F R} \\
& +R E C_{J E x N Z}+R E C_{J E x F R}+R E C_{N Z x F R},
\end{aligned}
$$

where $y$ is the phenotypic record, GLcat is the GL category, $D o b$ is the Julian day of the year the cow was born, $C G$ is the contemporary group effect, age is the age at calving in days, breed is the breed class (only Jersey, Holstein-Friesian and their crosses were included), age.breed is the fixed linear regression of age at calving in days nested within breed, $H F_{N Z}$ and $H F_{F R}$ are fixed linear regressions of New Zealand and foreign Holstein-Friesian breed composition, and HET and $R E C$ are fixed linear regressions of breed-specific heterosis and recombination effects, respectively (as described below).

Heterosis and recombination were calculated for specific breed combinations and over all breeds (Dickerson, 1973). Breed-specific values were calculated as

$$
\begin{gathered}
\text { heterosis }=P s(A) P d(B)+P s(B) P d(A), \\
\text { recombination }=P s(A) P s(B)+\operatorname{Pd}(B) P d(A),
\end{gathered}
$$



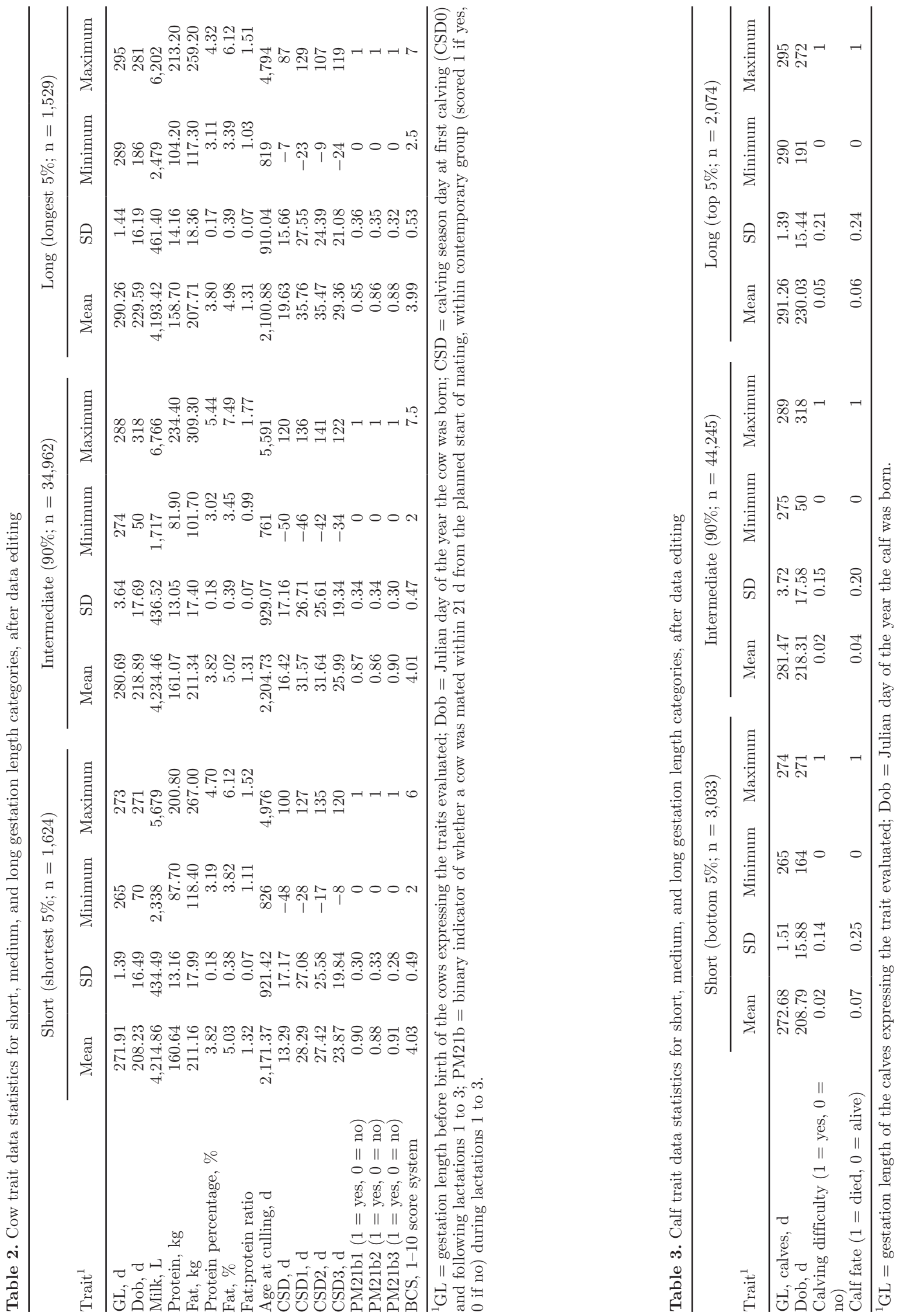
where $s=$ sire, $d=$ dam, $A=$ breed $1, B=$ breed 2 , and $P$ was the proportion of breed $\mathrm{A}$ or $\mathrm{B}$ in sire or dam breed composition.

Heifer CSD was analyzed as

$$
\begin{aligned}
y & =G L c a t+D o b+C G+\text { breed }+ \text { Dob breed }+H F_{F R} \\
& +H F_{N Z}+H E T_{J E x N Z}+H E T_{J E x F R}+H E T_{N Z x F R} \\
& +R E C_{J E x N Z}+R E C_{J E x F R}+R E C_{N Z x F R},
\end{aligned}
$$

where model parameters are the same as described for other fertility traits above. The difference was that Dob-breed was fitted instead of age-breed; that is, the linear regression of the Julian day of the year the heifer was born nested within breed. In this case, the model was run twice, once with Dob and Dobbreed fitted and once with neither of these effects fitted.

Production traits were analyzed using the model

$$
\begin{aligned}
y & =G L c a t+D o b+C G+\text { age }+ \text { breed }+ \text { age } \cdot \text { breed } \\
& +H F_{F R}+H F_{N Z}+H E T_{J E x N Z}+H E T_{J E x F R}+H E T_{N Z x F R} \\
& +R E C_{J E x N Z}+R E C_{J E x F R}+R E C_{N Z x F R},
\end{aligned}
$$

where all model parameters are as described above, except age, which is the age at the first cow calving (parity 1) for all production traits.

Body condition score was analyzed as

$$
\begin{aligned}
y & =G L c a t+D o b+C G+\text { type }+ \text { age }+ \text { breed }+ \text { age } \cdot \text { breed } \\
& + \text { age } e^{2} \cdot \text { breed }+ \text { stage } \cdot \text { breed }+ \text { stage } e^{2} \cdot \text { breed }+H F_{F R} \\
& +H F_{N Z}+H E T_{J E x N Z}+H E T_{J E x F R}+H E T_{N Z x F R} \\
& +R E C_{J E x N Z}+R E C_{J E x F R}+R E C_{N Z x F R}
\end{aligned}
$$

where model parameters are as described above, with the exception of age, which is the age at first cow calving (parity 1), and additional parameters stage, which is the stage of lactation in days at day of BCS measurement, and type, which is the effect of type of measurement, either progeny test (PT) or traits other than production (TOP), as described in Pryce and Harris (2006).

Age at culling (CullAge) was analyzed using the model

$$
\begin{aligned}
y & =G L c a t+D o b+C G 1+\text { breed }+H F_{F R}+H F_{N Z} \\
& +H E T_{J E x N Z}+H E T_{J E x F R}+H E T_{N Z x F R}+R E C_{J E x N Z} \\
& +R E C_{J E x F R}+R E C_{N Z x F R}
\end{aligned}
$$

where model parameters are as described above, but $C G 1$ is the contemporary group at first calving.
Calf fate and calving ease were analyzed as

$$
\begin{aligned}
y & =G L c a t+D o b+C G+\text { sireCode }+ \text { ageD }+ \text { breed } D \\
& + \text { sex }+ \text { breed }+ \text { age } D \cdot \text { breedD }+ \text { sex } \cdot \text { breed }+d H F_{F R} \\
& +d H F_{N Z}+H F_{F R}+H F_{N Z}+d H E T_{J E x N Z}+d H E T_{J E x F R} \\
& +d H E T_{N Z x F R}+d R E C_{J E x N Z}+d R E C_{J E x F R}+d R E C_{N Z x F R} \\
& +H E T_{J E x N Z}+H E T_{J E x F R}+H E T_{N Z x F R}+R E C_{J E x N Z} \\
& +R E C_{J E x F R}+R E C_{N Z x F R},
\end{aligned}
$$

where model parameters are as described above, with the addition of parameters sireCode, which is the sire official code, ageD, which is the age of the dam in days at calving, breedD, which is the breed of the dam, sex, which indicates the sex of the calf, $d H F_{i, F R}$, which is the linear regression of foreign Holstein-Friesian breed composition of the dam, $d H F_{i, N Z}$, which is the linear regression of New Zealand Holstein-Friesian of the dam, and $d H E T$ and $d R E C$, which are the linear regressions of breed-specific heterosis and recombination effects, respectively, of the dam.

\section{RESULTS AND DISCUSSION}

\section{Effect of GL on Fertility}

Gestation length category had a significant effect on CSD at first calving, even when Dob was accounted for (Table 4). Specifically, the short-GL heifers calved earlier $(3.1 \mathrm{~d})$ than those in the intermediate GL category. Heifers in the long GL category calved later (3.2 d later, $P<0.01)$. The effect of GL category on heifer calving remained strong after the effect of Dob was accounted for. This implies that both a short GL in utero and being born earlier in the year provide a fertility advantage to the heifer at her first calving, perhaps because it gives her the opportunity to mature (and reach puberty) earlier.

The magnitude of the effects of the cow's own GL category on her subsequent CSD trait values were variable as the cow aged; however, the effect remained relatively high and positive after including the effects of earlier birth of short-GL heifers in the effect of GL category (Table 4). That is, cows gestated for shorter periods in utero themselves tended to continue to calve earlier as cows, whereas cows gestated for longer tended to calve later. This positive linear relationship between GL category and fertility was also found by Norman et al. (2011), in relation to the mating related trait days open. In the current study, differences in mating trait values between the GL categories followed a pattern similar to that observed with the calving traits. That 
Table 4. Least squares solutions (SE) for short (bottom 5\%) and long (top 5\%) gestation length direct categories (glCat) compared with intermediate glCat (90\% data not in the tails of the distribution $)^{1}$

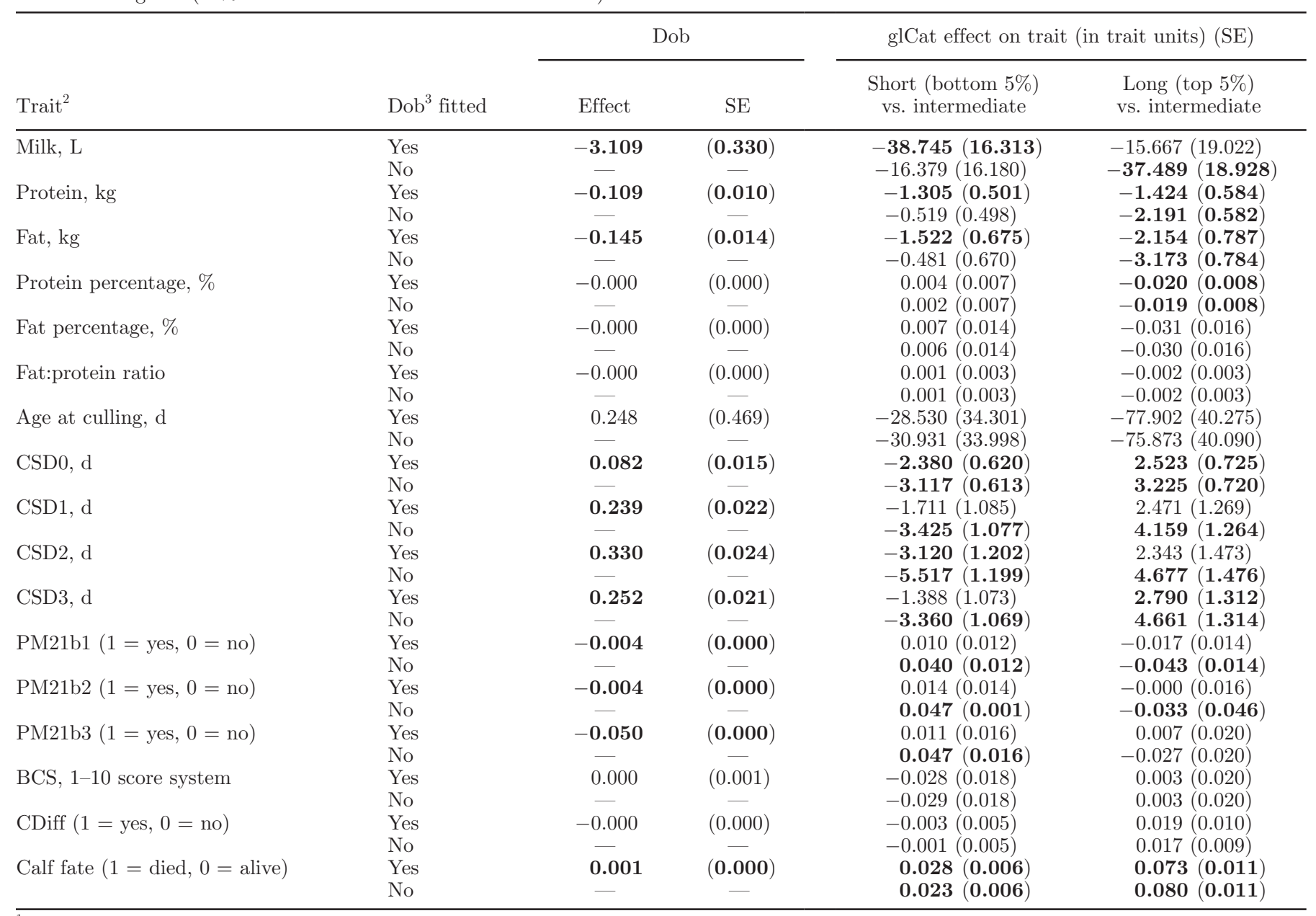

${ }^{1}$ Results are shown with and without adjustment for date of birth (Dob) and Dob effects in trait units per day are shown along with their standard errors. Significant differences $(P$-values $<0.05)$ are bolded.

${ }^{2} \mathrm{CSD}=$ calving season day at first calving (CSD0) and following lactations 1 to 3 ; PM21b = binary indicator of whether a cow was mated within $21 \mathrm{~d}$ from the planned start of mating, within contemporary group (scored 1 if yes, 0 if no) during lactations 1 to 3 ; CDiff $=$ calving difficulty scored 1 if a difficult calving recorded, and 0 otherwise.

${ }^{3}$ Dob $=$ Julian day of the year the cow was born.

is, cows born earlier due to shorter GL were more likely to be mated earlier in the season than cows that were born later due to being gestated for longer (Table 4).

These results show that the main fertility benefit of cows born following a short GL is the inherited direct genetic effect leading to shorter gestation length of calves. The shorter gestation lengths in their calves means that the cow calves earlier in the season, and thus has more opportunity to be mated early in the season and also to calve earlier. The benefits do not appear to compound over parities, perhaps partly because earlier calving cows commonly have a longer period from calving until a fixed planned start of mating that applies across the whole herd due to the seasonal calving system used in the New Zealand.

\section{Effect of GL on Production Traits and BCS}

Norman et al. (2011) found that cows that performed the best for milk production tended to be gestated for intermediate periods. These results are supported by the findings of this study, where GL category was a significant predictor of milk volume, protein and fat yields, and protein percentage, with shorter and longer gestated cows tending to produce less milk, protein, and fat (Table 4). Specifically, the effect of being in the short GL category was significant when any benefits from earlier birth were removed, with cows gestated for a shorter period before their birth tending to produce less milk volume and solids if born at the same time as other cows (Table 4). This effect became insignificant 
when the effect of Dob was included in the statistical model. Thus, there is some evidence that shorter GLd calves (born on the same day of the year as longer GL calves) have slightly lower milk production when they mature into cows, but these differences are offset by the benefit of being born earlier due to their short GL. Heifers achieving larger live weights at first mating are known to have higher milk production on average (Dobos et al., 2001; Carson et al., 2002; Macdonald et al., 2005; McNaughton and Lopdell, 2013). Indeed, when live weight was fitted as an alternative covariate in the milk production analyses instead of Dob, the GL category remained not significant (G. M. Jenkins, unpublished data). This means that shortening the GL is not expected to result in a significant decrease in milk production, given that the resulting heifer calves are born earlier in the season and have a chance to reach optimal live weight before lactation. Protein and fat yields were significantly lower for cows in the longest GL category, regardless of whether Dob was accounted for (Table 4). Fat percentage was not significantly affected by GL category, and protein percentage was not significantly affected in cows in the short GL category, although there was a significant and small decrease in protein percentage in cows gestated for longer (Table 4).

Overall, these results suggest that, in seasonal calving systems such as those operated in New Zealand, a significant decrease in milk production for cows gestated for a shorter period should not be expected and there is more likely to be a decrease in production in cows gestated for longer. Therefore, reducing GL in the population through direct or indirect selection should have a neutral or positive effect on future cow production. Neither Dob nor a cow's GL category significantly influenced BCS.

\section{Effect of GL on Cow Survival, Calving Difficulty, and Calf Fate}

Short GL did not result in statistically significant reductions in the subsequent survival of cows that achieved a first lactation. Although nonsignificant, the direction of the effects matched those reported by Norman et al. (2011). Cows gestated for an intermediate period experienced more desirable culling ages, and cows gestated for shorter periods experienced less of a reduction in cull age than cows gestated for longer periods. It is worth noting that due to data availability, these results pertain to cows that at least achieve a first lactation. Heifers reared to become replacements that fail to be mated are not included in the data set; therefore, if they had been culled early for reasons re- lating to GL, this would not have been detected in the current study.

The $t$-test for the effect of the long GL category on calving difficulty was significant, with long GL calves more likely to be associated with calving difficulty than short or intermediate GL calves (Table 4). Although the $F$-test for the effect of GL on calving difficulty was not significant, it tended toward significance and the direction of the effects matched was as expected (Table 4) based on the literature (Hansen et al., 2004; Jamrozik et al., 2005).

Calves that were gestated for shorter periods were more likely to die in the perinatal period than intermediate-GL calves (Table 4). This is consistent with Bleul (2011), who found a significant increase in perinatal mortality in short-GL calves. The present study also found that calves gestated for longer periods were more likely to die in the perinatal period and the magnitude of the effect was 3 times that of the short-GL calves (Table 4). Some other studies identified associations only between long gestation and perinatal mortality (McGuirk et al., 1998; Chassagne et al., 1999), whereas others have found both extremes of GL to be more associated with perinatal mortality than the intermediate GLd phenotypes (Johanson and Berger, 2003; Hansen et al., 2004; Norman et al., 2011). The association between long GL and perinatal mortality is almost certainly due to higher incidences of dystocia following a long gestation, which is supported in this study by the association between long GL and calving difficulty. Any concerns about a reduction in calf survival resulting from either direct or indirect selection for shorter GL could be alleviated by computing an EBV for a calf survival trait and including it in the national breeding objective. Such a penalty would also penalize animals with a genetic propensity for long GL if the long GL led to lower rates of calf survival.

\section{CONCLUSIONS}

Reducing average GL as an outcome of either direct (inclusion in the breeding objective) or indirect (inclusion in the fertility genetic evaluation prediction model as a correlated trait) selection criteria is unlikely to result in a significant decrease in milk production but should have a positive effect on fertility. Shorter GL cows are more likely to calve earlier and present for mating earlier in the season. Selection for reduced GL should not negatively affect BCS, survival, or calving difficulty, whereas the calf mortality disadvantage of more calves with very short GL should be offset by a reduction in numbers of very long GL calves, who have the highest levels of calf mortality. Overall, the net 
effects of any genetic selection that results in shorter GL are likely to be economically positive in the New Zealand seasonal calving dairy system.

\section{ACKNOWLEDGMENTS}

This project is funded by New Zealand dairy farmers through DairyNZ Incorporated (Hamilton, New Zealand) and the Ministry of Primary Industries through the Primary Growth Partnership (Wellington, New Zealand). The authors acknowledge Livestock Improvement Corporation (LIC) for supplying core (CDAP\#46) and non-core (LIC62) data for analysis.

\section{REFERENCES}

Bleul, U. 2011. Risk factors and rates of perinatal and postnatal mortality in cattle in Switzerland. Livest. Sci. 135:257-264.

Carson, A. F., L. E. R. Dawson, M. A. McCoy, D. J. Kilpatrick, and F. J. Gordon. 2002. Effects of rearing regime on body size, reproductive performance and milk production during the first lactation in high genetic merit dairy herd replacements. Anim. Sci. 74:553-565.

Chassagne, M., J. Barnouin, and J. P. Chacornac. 1999. Risk factors for stillbirth in Holstein heifers under field conditions in France: A prospective survey. Theriogenology 51:1477-1488.

DairyNZ. 2007. Contemporary groups for New Zealand standard dairy herd testing. Accessed Mar. 18, 2015. http://www.dairynz.co.nz/ media/580117/Contemporary-Grouping-May-2007.pdf.

Dickerson, G. E. 1973. Inbreeding and heterosis in animals. Pages 5477 in Proc. Animal Breeding and Genetics Symposium in Honor of Dr. Jay L. Lush, Blacksburg, Virginia. Am. Dairy Sci. Assoc., Champaign, IL.

Dobos, R. C., K. S. Nandra, K. Riley, W. J. Fulkerson, I. J. Lean, and R. C. Kellaway. 2001. Effects of age and liveweight at first calving on first lactation milk, protein and fat yield in Friesian heifers. Aust. J. Exp. Agric. 41:13-19.
Donoghue, K. A., R. Rekaya, and J. K. Bertrand. 2004. Comparison of methods for handling censored records in beef fertility data: Field data. J. Anim. Sci. 82:357-361.

Hansen, M., M. S. Lund, J. Pederson, and L. G. Christensen. 2004. Gestation length in Danish Holsteins has weak genetic associations with stillbirth, calving difficulty, and calf size. Livest. Prod. Sci. 91:23-33.

Harris, B. L., J. E. Pryce, Z. Z. Xu, and W. A. Montgomerie. 2006. Development of new fertility breeding values in the dairy industry. Proc. N.Z. Soc. Anim. Prod. 66:107-112.

Jamrozik, J., J. Fatehi, G. J. Kistemaker, and L. R. Schaeffer. 2005. Estimates of genetic parameters for Canadian Holstein female reproduction traits. J. Dairy Sci. 88:2199-2208.

Johanson, J. M., and P. J. Berger. 2003. Birth weight as a predictor of calving ease and perinatal mortality in Holstein cattle. J. Dairy Sci. 86:3745-3755.

Macdonald, K. A., J. W. Penno, A. M. Bryant, and J. R. Roche. 2005. Effect of feeding level pre- and post-puberty and body weight at first calving on growth. J. Dairy Sci. 88:3363-3375.

McGuirk, B. J., I. Going, and A. R. Gilmour. 1998. The genetic evaluation of beef sires used for crossing with dairy cows in the UK 1. Sire breed and non-genetic effects on calving survey traits. Anim. Sci. $66: 35-45$.

McNaughton, L. R., and T. Lopdell. 2013. Effect of heifer live weight on calving pattern and milk production. Proc. N.Z. Soc. Anim. Prod. 73:103-107.

Norman, H. D., J. R. Wright, and R. H. Miller. 2011. Potential consequences of selection to change gestation length on performance of Holstein cows. J. Dairy Sci. 94:1005-1010.

Pryce, J. E., and B. L. Harris. 2006. Genetics of body condition score in New Zealand dairy cows. J. Dairy Sci. 89:4424-4432.

Roche, J. R., P. G. Dillon, C. R. Stockdale, L. H. Baumgard, and M. J. VanBaale. 2004. Relationships among international body condition scoring systems. J. Dairy Sci. 87:3076-3079.

SAS Institute. 2014. SAS software. Version 9.4. 3rd ed. SAS Institute Inc., Cary, NC.

Winkelman, A. M., and R. J. Spelman. 2001. Selection for reduced gestation length in New Zealand dairy cattle. Proc. Assoc. Advmt. Anim. Breed. Genet. 14:63-66. 